\title{
KULEUVEN
}

\begin{tabular}{|c|c|}
\hline Citation & $\begin{array}{l}\text { van Achterberg, T. (2012), } \\
\text { CALL FOR PAPERS: Examination of Basic Nursing Care } \\
\text { Journal of Nursing Scholarship, } 44(4), 313-314\end{array}$ \\
\hline Archived version & $\begin{array}{l}\text { Post-print. Author manuscript: the content is virtually identical to the content } \\
\text { of the published paper, but without the final typesetting by the publisher }\end{array}$ \\
\hline Published version & http://dx.doi.org/10.1111/j.1547-5069.2012.01481.x \\
\hline Journal homepage & http://onlinelibrary.wiley.com/journal/10.1111/(ISSN)1547-5069 \\
\hline Author contact & $\begin{array}{l}\text { Theo.vanAchterberg@med.kuleuven.be } \\
\text { + } 32(0) 16373301\end{array}$ \\
\hline IR & https://lirias.kuleuven.be/cv?u=U0090873 \\
\hline
\end{tabular}

(article begins on next page) 


\section{CALL FOR PAPERS: Examination of Basic Nursing Care}

Manuscripts on basic nursing care are sought for the First Quarter 2014 issue of Journal of Nursing Scholarship. Manuscripts should follow Author Guidelines available at http://www.wiley.com/bw/submit.asp?ref=1527$\underline{6546}$ and must be submitted no later than June 1, 2013. Please indicate in your cover letter and on your title page that the manuscript is being submitted for this special issue.

Note from the guest editor of this special issue:

Basic nursing care serves nearly all people in their lifetimes. Infants, adults, and elderly alike may need physical or psychosocial nursing care as a result of disease or incapacity, either temporarily or permanently. Also, basic care is generic across medical conditions and care settings. Yet, this most common type of nursing care is surprisingly ill informed by evidence, and its quality can be insufficient.

In the nursing literature over the years, both the quality and clinical relevance of nursing research have shown limitations (Rahm Hallberg, 2009), with limited contributions to the body of knowledge in nursing as a result. Moreover, nursing research has shown increasing development in specialist areas (e.g., cancer nursing, cardiovascular nursing, neurology nursing, etc.). Generating and synthesizing evidence on generic basic care have received less attention.

This is reflected in the overview of systematic reviews on nursing care available in the Cohrane Library (www.cncf.cochrane.org), where systematic reviews in important generic areas such as respiration, temperature control, sleep and rest, oral care, nutrition, and dehydration are lacking, both for inpatient and outpatient or community based nursing care. If reviews on these care issues are performed at all, they focus on very specific conditions, such as oral care following tonsillectomy (Fedorowicz, Al-Muharraqi, Nasser, Al-Harthy, \& Carter, 2011) or parenteral nutrition in acute pancreatitis (Al-Omran, AlBalawi, Tashkandi, \& Al-Ansary, 2010).

While the development of evidence on basic nursing care needs urgent attention, it would be over simplistic to claim a total absence of evidence in this area. Especially in the area of prevention of common complications, substantial evidence and guidelines are available to inform nursing actions. Pressure ulcer prevention (www.epuap.org/guidelines) and infection prevention through hand hygiene (www.who.int/gpsc/en/) are clear examples of this. In these and similar areas, however, a lack of implementation is seen (Van Achterberg, Schoonhoven, \& Grol, 2009). Though many have already tried to increase the uptake of hand hygiene guidelines, for instance, evidence of effects commonly refer to short-term follow-up, and substantial room for improvement still remains (Huis, van Achterberg, de Bruin, Grol, Schoonhoven, \& Hulscher, 2012). So while generating evidence for basic nursing care needs to be addressed, we also need to look into the implementation of the evidence that is already there.

Exactly what is "basic nursing care?" Its nature is probably best described by Kitson and colleagues (2010), who recently undertook a meta-narrative review aimed at defining what they refer to as the fundamentals of care. Though Kitson and colleagues encountered a large variety of terminology and variable agreement between authors, their review arrived at a first set of elements to illustrate what basic care or the fundamentals of care are about. They include care for communication, breathing, eating and drinking, elimination, cleanliness and dressing, mobility, activities, rest, sleep, body 
temperature, working and playing, expressing sexuality, care for safety (prevention of complications), and death care.

Given this first set of basic nursing care issues, the limitless range of application, the limited evidence to support basic care, and the insufficient uptake where evidence is available, we need to look at basic care. The Journal of Nursing Scholarship wishes to devote a special issue to this core of nursing. Nurse scientists are encouraged to submit original research, or systematic overviews of studies looking into evidence for basic nursing care or care improvement through the uptake of evidence already available in this area.

\section{Theo van Achterberg, PhD, RN, FEANS}

Guest Editor and Board Member

Journal of Nursing Scholarship

Scientific Institute for Quality of Healthcare

Radboud University Nijmegen Medical Centre

Nijmegen, The Netherlands

\section{References}

Al-Omran, M., AlBalawi, Z.H., Tashkandi, M.F., Al-Ansary, L.A. (2010). Enteral versus parenteral nutrition for acutepancreatitis. Cochrane Database of Systematic Reviews, 1. Art. No.: CD002837. Retrieved from http://onlinelibrary.wiley.com/doi/10.1002/14651858.CD002837.pub2/full DOI: 10.1002/14651858.CD002837.pub2

Fedorowicz, Z., Al-Muharraqi, M.A., Nasser, M., Al-Harthy, N., \& Carter. B. (2011). Oral rinses, mouthwashes and sprays for improving recovery following tonsillectomy. Cochrane Database of Systematic Reviews, 7. Art. No.: CD007806. Retrieved from http://onlinelibrary.wiley.com/doi/10.1002/14651858.CD007806.pub3/full DOI: 10.1002/14651858.CD007806.pub3.

Huis, A., van Achterberg, T., de Bruin, M., Grol R., Schoonhoven, L., \& Hulscher, M. (2012). A systematic review of hand hygiene improvement strategies: A behavioural approach. Implementation Science, 7(1), 92. Retrieved from http://www.implementationscience.com/content/7/1/92/abstract

Kitson, A, Conroy, T, Wengstrom, Y, Profetto-McGrath, J, \& Robertson-Malt, S. (2010). Defining the fundamentals of care. International Journal of Nursing Practice, 16(4), 423-434.

Rahm Hallberg I. (2009). Moving nursing research forwards towards a stronger impact on health care? International Journal of Nursing Studies, 46(4), 407-412.

Van Achterberg, T., Schoonhoven, L., \& Grol, R. (2008). Nursing implementation science: How evidence-based nursing requires evidence-based implementation. Journal of Nursing Scholarship, 40, 302-310. 